\title{
Exploration of JPMorgan Chooser Option Pricing
}

\author{
Ziheng Huang ${ }^{1, \dagger}$, Xinyu Wang ${ }^{2, \dagger}$, Wenbin Wan ${ }^{3,}{ }^{*}, \dagger$ \\ 1. Business College, Sichuan University, 610000, Chengdu, China \\ 2. Business College, Nanjing University, 210023, Nanjing, China \\ 3. College of Arts and Sciences \& Fisher College of Business, The Ohio State University, 43210, \\ Columbus, US \\ *wan.405@osu.edu \\ † These authors contributed equally
}

\begin{abstract}
As the development of the capital market, the derivatives of financial instruments have been active in the financial market. Investors can trade customized derivatives designed to manage increasingly complex risk exposures. Examples of exotic options satisfying demands include the chooser option. Most contracts require the holder to commit to a particular payoff profile at the outset, which may often be unattractive for some potential investors. Therefore, we choose the stocks of JPMorgan and use the Black-Scholes model to simulate the value of the chooser option. This article suggests approximating the value on two periods and aims to set the value of the chooser option of JPMorgan, constructs the reasonable expectation for investors, and enables them to make the proper decision on the chooser options. We provide reliable option values and retains the flexibility of simulation, in that it allows great freedom in decision date when the investors decide which type of option for the underlying assets or a joint process for the asset price, its volatility, and other asset prices. From the simulation results, we conclude that although the chooser option is the same as the traditional option in nature, the chooser option puts off the decision date and makes the payoff less volatile to the movement of the stock market, thus partly hedge the risks of the stock market.
\end{abstract}

Keywords: Capital Market; Black-Scholes Model; Stock Market.

\section{Introduction}

Exotic option, first emerged in 1997 and named Asian Option, is favored, and studied by investors and researchers in the 1990s for its high-risk and high payouts [1]. Exotic Options have then become an area that attracts investors' attention, and many other exotic options occur makes the combinations of financial investing more than we can previously think of. Compared with other traditional American Options and European options, which have few combinations or investing methods, the exotic options can have more operation choice and the final return depending on the strike price [24].

Among all the exotic options, our research team chose one of the most representative ones - the chooser option. In the usual case, the mature times are different for the call options and put options and have different operation costs [5]. However, in simple Chooser Options, the strike price of call and put options are the same [6]. Thus, the investors only need to consider whether the price will fall below or rise above the strike price, which is very convenient for the consumers.

The chooser option is classified into two categories as the European chooser option and the American chooser option. The European chooser option gives the holder the right to choose at the maturity date, the best of a European put and a European call. Its exercise payoff is the maximum of strike price and stock price. The American chooser option can be exercised at any time before its own maturity date. The holder selects an American put or calls with a maturity date. Various contracts of this type were written by Banker Trust during the 1990s. Assets underlying the options have included commodities and indices. For this contract, the underlying option carries implicit dividends as they may be optimally exercised before their own maturity date. Early exercise of the American chooser option may therefore become beneficial and in that event, the contract value will differ from the European chooser value. In this paper, we express the European chooser option. 
The basic idea of valuing the payoffs of the exotic option has been recognized in previous publications. In terms of binaries option, Rubinstein and Reiner [1] have demonstrated their relationship to barrier options, while Ingersoll [7] extends the idea by expressing complex derivatives in terms of 'event driven' binaries. These latter binaries pay either one unit for stock or one unit of cash it and only an event occurs. As the BS framework, we use here is a type of dynamic hedging leading to the unambiguous equation for pricing all derivative contracts [8].

When the underlying assets follow diffusion dynamics, the following two methods are both applied for pricing options. The more popular way is the expectation method, in which the price of any derivative can be expressed as the discount expected payoff under the equivalent martingale measure. The second approach is the partial differential equation (PDE) method in which the option price is expressed as the solution of a parabolic PDE with given terminal conditions. Both methods have clear representations of the dynamic hedging procedures. In this paper, the PDE method is used to express the chooser option. The benefit of using the BSM framework lies in the wider application of the pricing model in constructing other exotic options.

The Our research team has specific research on the valuation chooser options and uses the firm JPMorgan \& Chase Co. We aimed to provide some guidance for the investors to have a higher probability of earning before the maturity date. Our paper is primarily written in the flow of firm description, an explanation on the chooser option model, the analysis of our research outcomes.

\section{Firm Description}

\subsection{Brief Background}

JPMorgan Chase \& Co., a multinational investment bank and financial service company in the US is the analysis target for our research team. As the data reported at the end of 2020 by the US feudal financial institution, JPMorgan Chase \& Co. is the largest bank in the US with a total Assets of \$3,386 billion [9] and is also the fourth largest bank all over the world [10] after the merge of JPMorgan and Chase Manhattan Co. in 2000 [11]. The research done by a research team [12] states that the merger of banks in under a condition of growing markets which enhanced revenue, and the merger of J.P. Morgan and Chase Manhattan to form J.P. Morgan Chase was estimated to produce a cost savings of $\$ 1.5$ billion, this action not only led the products to more abundant client bases but also lead to the sustainability of many businesses. With the base of a large amount of asset, the JPMorgan Chase \& Co. even have a business field like technology [13]. Up to now, it has had a very diverse business field including Banking, Health Care, Business consultant, Asset Management, and a lot of other business-related projects. This varies business field made the firm more profitable and worth investing for the investors.

\subsection{Financial Situation and Stock Prices}

The recent CNBC report [14], reported that the second-quarter profit and revenue of JPMorgan Chase \& Co. exceeded analysts' expectations as the banking giant released money set aside for loan losses. These actions could help the economic recovery and the financial stability of the whole society. Though the trading value had fallen roughly $30 \%$ earlier this year due to the Federal reserves' action, this is a common outcome for all the banks in the US. To better understand how this firm is working after the great merge, our team downloaded the historical stock price from Yahoo finance after 2000 and make two graphs of the stock price to show the overall growth trend of the firm - one is the price after the merge action, the other is the reaction of Morgan's stock reactions under the influence of COVID-19 condition. From the graphs, it is obvious that the overall growth trend of the two graphs is upward growing. Though there are some down points in some historical points and such a great fall due to the influence of the virus condition, it did have good behavior on the economic recovery. 


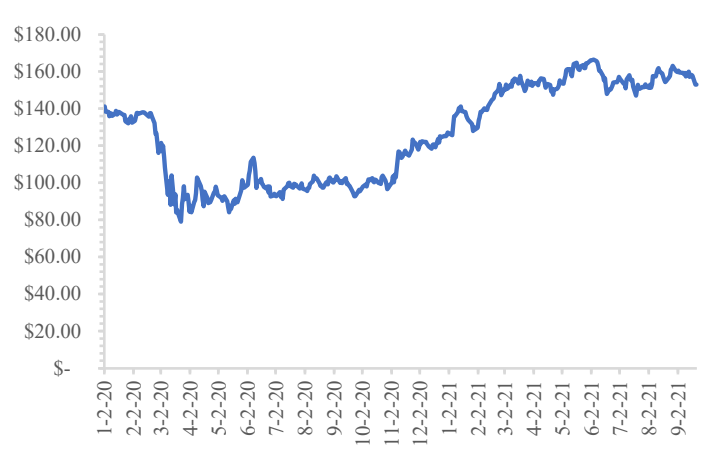

Figure 1. Stock Price of JPMorgan Chase \& Co.

Here is the annual report of JPMorgan, stockholder return, financial highlight. [15]

Table 1. Annual report of JPMorgan

\begin{tabular}{|c|c|c|c|c|c|c|}
\hline For the year ended December 31, (in millions) & \multicolumn{2}{|r|}{2020} & \multicolumn{2}{|r|}{2019} & \multicolumn{2}{|c|}{2018} \\
\hline \multicolumn{7}{|l|}{ Selected income statement data } \\
\hline Total net revenue & $\$$ & 119,543 & s & 115,399 & $\$$ & 108,783 \\
\hline Total noninterest expense & $\$$ & 66,656 & $\$$ & 65,269 & $\$$ & 63,148 \\
\hline Pre-provision profit & $\$$ & 52,887 & $\$$ & 50,130 & $\$$ & 45,635 \\
\hline Provision for credit losses & $\$$ & 17,480 & $\$$ & 5,585 & $\$$ & 4,871 \\
\hline Net income & $\$$ & 29,131 & $\$$ & 36,431 & $\$$ & 32,474 \\
\hline \multicolumn{7}{|l|}{ Per common share data } \\
\hline \multicolumn{7}{|l|}{ Net income per share: } \\
\hline Basic & $\$$ & 8.89 & $\$$ & 10.75 & $\$$ & 9.04 \\
\hline Diluted & $\$$ & 8.88 & $\$$ & 10.72 & $\$$ & 9.00 \\
\hline Book value per share & $\$$ & 81.75 & $\$$ & 75.98 & $\$$ & 70.35 \\
\hline Tangible book value per share & $\$$ & 66.11 & $\$$ & 60.98 & $\$$ & 56.33 \\
\hline Cash dividends declared per share & $\$$ & 3.60 & $\$$ & 3.40 & $\$$ & 2.72 \\
\hline
\end{tabular}

\section{The Pricing Model of the Chooser Option}

\subsection{Definition of a Chooser Option}

A chooser option is an option contract that allows the holder to decide whether it is to be a call or put before the maturity date. When the contract is made, the investors have the right to put off the decision date and make the decision based on the first-period payoff. According to the stock performance in the first period, the investors have easy access to predicting the future payoff more reasonably. Therefore, there is more probability for investors to gain.

In the first period, the investors do not have to make decisions, so there exists a period that the option could benefit from upside or downside movement. A great deal of flexibility provided for investors makes it more expensive than ordinary European options.

\subsection{Comparison with Typical European Option}

Although the chooser option is an exotic option that postpones the decision date and improves the reasonableness and credibility of prediction, the nature of the chooser option has not changed. Same as typical European options, chooser options have one strike price and one expiration date regardless of whether the option is exercised as a call or put.

Chooser options are constructed on the expectation and predictions of investors. The changes in the underlying value and changes in volatility belief make what the chooser option it is. It is also noticeable that when the investors are predicting there will be some movements in the capital market but are not sure that the direction of the movements, chooser options are a good choice. 


\subsection{Pricing Model of a Chooser Option}

From the discussion above, we constructed a pricing model of the chooser option using the BlackScholes pricing model. The BSM model assumed future stock prices were lognormally distributed and rick neutrality which shows that for options and future pricing, we can pretend that there is no risk premium, but of course the risk premium is already part of the stock price or the future price.

In our process of pricing, we assume the JPM chooser option will mature after one year. And the investors can make decisions at any time during the year before the expiration date.

\subsubsection{Parameters}

From the data sources above, we assess August 2019 to August 2021 JPM stock price, and we set 156.7 which is the stock price on 23, August 2021 as the parameter. Sigma is the historical volatility based on the stock price from August 2020 to August 2021, which we assume the later the date, the more accurate of future volatility. The following is the parameter we have used. As for the strike price, we have used the CME option strike price on 23, August 2021 for simulation

Table 2. Some Parameters in listed banks

\begin{tabular}{|c|c|}
\hline Parameters & Amount \\
\hline Stock price & $\$ 156.7$ \\
\hline Risk free rate & $0.15 \%$ \\
\hline sigma & $28.2 \%$ \\
\hline Strike price & $\$ 150$ \\
\hline Dividend yield & $2.33 \%$ \\
\hline T1 & 0.5 \\
\hline T2 & 1 year \\
\hline \multirow{2}{*}{ Reference item } & T1 is the decision date whether the option is to call or put. \\
& T2 is the maturity date of the chooser option. \\
\hline
\end{tabular}

\subsubsection{Pricing Model}

Black-Scholes model:

$$
S T=S 0 e^{\left(\alpha-\frac{1}{2} \sigma^{2}\right) T+z \sigma \sqrt{T}}
$$

Using the BSM, we input the parameters above and then compare the ST with the strike price, and the investors should choose the option when the ST is larger than the strike price. Then in the second six months, we also use the ST based on the first period and give the result of the new ST and again compare it with the strike price. Here we gain the different payoffs on the maturity date.

We divide the period of 1 year into two periods, one of which is between the contract date and the decision date and another of which is between the decision date and the maturity date. The cut-off point is random, here we set the first period as six months.

Table 3. Part of simulation results(10 simulations)

\begin{tabular}{|c|c|c|c|}
\hline \multicolumn{2}{|c|}{ 1 st Six-month } & \multicolumn{2}{|c|}{ 2 nd Six-month } \\
\hline ST/\$ & Choice Call/Put & ST(Based the first period)/\$ & Payoff/\$ \\
\hline 118.33 & PUT & 116.77 & 33.23 \\
\hline 222.63 & CALL & 192.89 & 42.89 \\
\hline 186.53 & CALL & 192.94 & 42.94 \\
\hline 164.08 & CALL & 148.77 & 0 \\
\hline 159.09 & CALL & 116.78 & 0 \\
\hline 186.73 & CALL & 128.12 & 59.48 \\
\hline 106.61 & PUT & 90.52 & 29.61 \\
\hline 163.06 & CALL & 179.61 & 5.18 \\
\hline 129.26 & PUT & 144.82 & 13.5 \\
\hline 115.41 & PUT & 136.50 & \\
\hline
\end{tabular}


In the first column, the STs (stock price) are captured from the Yahoo Finance website and the second column is our final simulation results, which are using the simulation method based on the BSM model and compare the ST here to the strike price. When the ST is larger than the strike price, then the choice in the first six months is call. Reversely, when the ST is smaller than the strike price, then the choice in the first six months is put.

The third and fourth columns are the second six months results and the related payoff. In the first period, the put or call in the second column means that the results in the second period are based on the choice made in the first period. And the payoffs related are shown in the last column.

\subsection{Discussion about the Simulation Results}

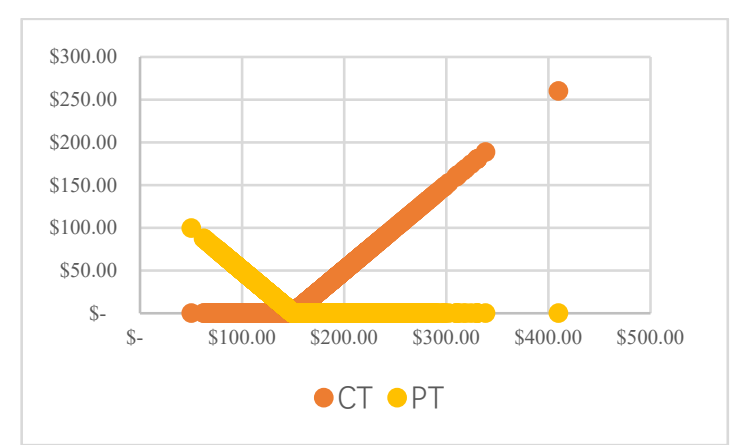

Figure 2. The $2^{\text {nd }}$ Six- month Stock price of call option and put option

From the table and the graph above, the final payoffs somehow reflect the nature same as the traditional options. The payoff shows that option can hedge the unfavorable movement in the capital market although some of the payoffs are zero. However, it is noticeable that the chooser option is the same as the traditional option which can not be completely profitable and there are always no gains and no losses. Therefore, the limitation of the chooser option is that the chooser option can only put off the decision date but cannot hedge all the risks in the capital markets. When the capital markets face the big ups and downs and it is difficult for the investors to predict, the chooser option is somehow losing the halo.

\section{Results Analysis}

For the first period call and put option value, using the simulation of the random variables which is like the fluctuations in the stock market, the call and put choices are also random. In the second period, the stock price is based on the first six months and after the choice of the call or put, the payoff is limited to the put or call.

In the final payoff, it is obvious that the payoff is positive and some of them are zero, which is helpful to hedge the risks and minimize the loss. It is also noticeable that there are some zero payoffs. It means that the chooser option payoff is not always positive, and the investors will not always enjoy the payoff.

Therefore, the nature of the chooser option bears not much different from the traditional options. Chooser options help to put off the decision-making date for investors but still cannot step closer and hedge all risks of the big movement in the capital markets.

Before, our team mainly simulated a random sample of market stock prices for the exploration of chooser option value. In the subsequent stage, parameters that had been presumed to be specific in the Black-Scholes model would be changed to see what impacts will have on chooser option values. The changing objects include volatility, strike price, Risk-free interest rate, and dividend yield.

\subsection{Volatility}

Volatility is a statistical measure of the dispersion of returns of a given market. It often refers to the amount of uncertainty and risk related to the frequency and size of changes in the price of an 
underlying asset. In many cases, volatility is often measured by the standard deviation $(\sigma)$ of price changes over a certain period [16].

In our basic simulation model, volatility can refer to either historical volatility or implied volatility. The former one, as the name suggests, is calculated by collecting price data and figuring out the standard deviation of average return rates in a given time. In our simulation model, it is always transferred to the annual volatility rate. Different from historical volatility implied volatility makes a forecast of the movement in the price. It is derived from the calculation that plugs the options trading price into the Black-Scholes formula [17].

During the simulation process, the team chose the latest year's historical volatility. To see how volatility will influence the option value, the team changed the $\sigma$ slowly and the result is demonstrated in the following graph.



Figure 3. Sensitivity analysis on sigma

It is evident that volatility significantly affects the option value. The higher the volatility, the higher is the price for both call and put options. The explanation is as follows. The high volatility means the stock price has a greater probability to swing over a larger range of values in either direction. In terms of call options, if the current stock price goes beyond the strike price, the buyer will exercise the options. Otherwise, he will allow the options to expire, which means the falling price has downside protection. Therefore, the increased volatility does not lose money on the downside but helps make money on the upside. The same thing applies to the put options. On the whole, higher volatility increases the call and put option values.

\subsection{Strike Price}

The strike price is the agreed price at which the holder of the option has a right to buy or sell an asset at some date in the future which has already be predetermined in the contract.

Strike price matters a lot to the value of the options. The maximum between zero $(0)$ and the absolute price difference between the market stock price and the strike price $(|\mathrm{ST}-\mathrm{X}|)$ decides the option's intrinsic value.

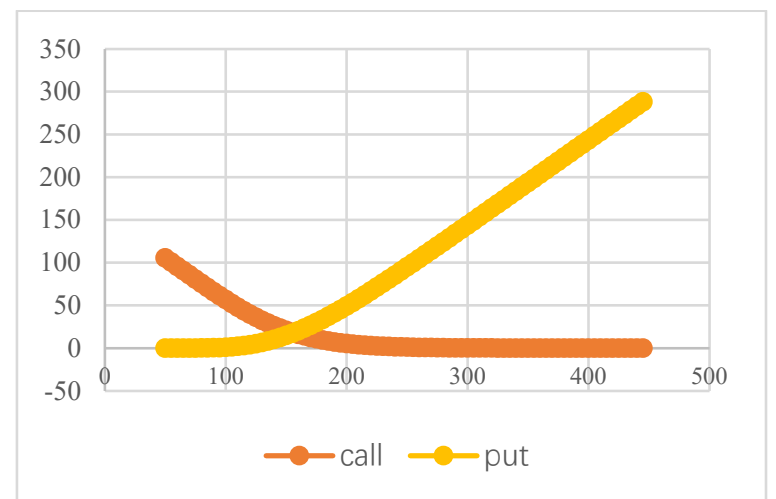

Figure 4. Sensitivity analysis on the strike price 
In the second step of the model test, the strike price was changed from small numbers to larger ones, and the market strike price $\$ 150$ at the time of the experiment was also included.

One of the most obvious conclusions is that when strike price increases, the call value decreases while the put value increases.

In terms of call options, the buyer and the seller reach an agreement that the buyer owns a right to buy a specified number of shares at a fixed price, and the seller should sell the shares at the strike price if the holder asks to exercise the options before the expiration date. In normal circumstances, the buyer of the call options selects to exercise the right only if the call options are in the ITM(in-themoney) position, which means the current market stock price has surpassed strike price and buyers profit per share by the difference between the market stock price and strike price(ST-X). [18]. If the call options stay OTM(out-of-the-money) until the expiration date, the options will not be exercised and they have no intrinsic value. [19]. When strike price goes up, the stock price will have less potential to surpass the strike price, contributing to smaller chances for call options to realize their intrinsic values in the same market. On average, the call value goes down if the strike price increases.

When it comes to put options, the seller has a right to exercise the options if they are in the ITM position, in which circumstance it means that the strike price is above the current market stock price, and put options profit per share by the difference between the strike price and the market stock price(X-ST). The OTM put options will have no value at all just as the OTM options do. Altogether, the higher strike price brings more possibilities for put options to realize the intrinsic values, which exactly indicates the higher put value.

\subsection{Risk-free Interest Rate}

The Risk-free rate of interest is one sort of interest rate which profits from investing money to an investment object without any risk. In American capital markets, the rate of treasury bonds is frequently used to measure it.

When it refers to the rate of return, if there is an all-known Risk-free rate of 5\%, the stock price of the underlying asset is usually expected to rise more than $5 \%$ on the whole since risk makes money; Otherwise, risk aversion mechanism will drive traders to merely consider trading with Risk-free bonds in return for fixed payoffs, which means that higher Risk-free interest rate corresponds to the higher expected rate of return. That's our basic assumption.

During the experiment process, to show how a Risk-free interest rate will impact the call and put value, the team kept changing the set numbers. The horizontal axis is the rate, and the vertical one shows the option value. The result is presented below.

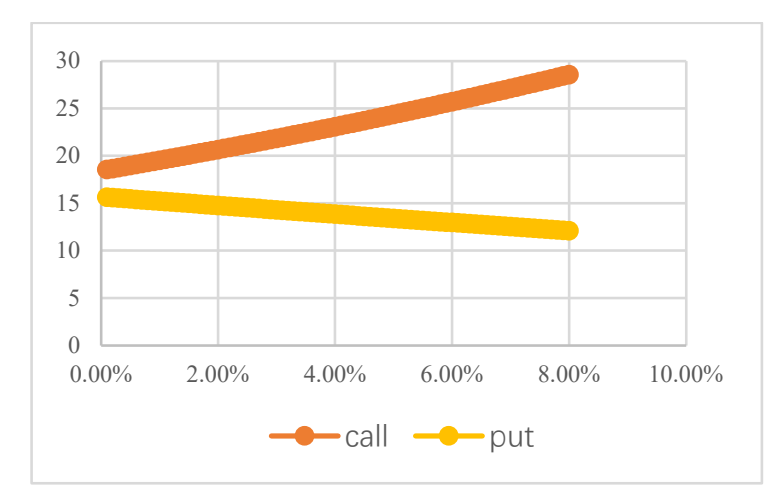

Figure 5. Sensitivity analysis on the Risk-free rate

There is a linear relationship between option values and Risk-free interest rates. The call option value is impacted positively by increasing interest rate while the put option value is impacted negatively.

In respect of call options, on the one hand, increasing the Risk-free interest rate brings about a higher expected rate of return of the stock in the future, which is a clear implication of the rising stock 
price of the underlying asset. Therefore, the intrinsic value of the call options(ST-X) has a tendency to grow. On the other hand, the higher Risk-free interest rate signifies a lower present value of future cash. A call option means a future purchase of the stocks at the strike price which equates to future cash outflows. The higher the Risk-free rate, the smaller amount of the present value of future cash outflows is and the more benefits buyers of call options will get, resulting in increased call value.

As for put options, impacts are the opposite. Firstly, increased probabilities of higher stock prices brought by increased Risk-free interest rates are not beneficial to holders of put options and this potential phenomenon lowers the intrinsic value of put options. Secondly, a put option is equivalent to a right to sell the stocks, and thus higher Risk-free rate leads to a smaller amount of present value of future cash inflows, which pushes the put option value to drop [20].

\subsection{Dividend Yield}

The dividend yields often expressed as a percentage; is the amount of money a company pays its shareholders per share divided by the current stock price. It discloses the payoff investors expect from the company and is always an important ratio for the public to measure the financial situation of the company [21].

In the simulation process, the team changed the value of dividend yield many times to check if it has something to do with the value of call and put options, and the result is demonstrated in the graph below.

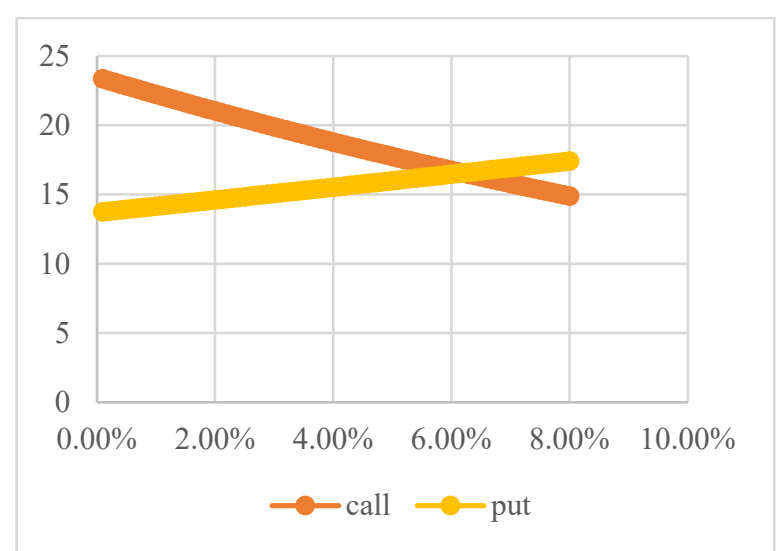

Figure 6. Sensitivity analysis on the dividend rate

As shown, a negative linear relationship is found between call value and dividend yield while a strong opposite relationship is indicated between put value and dividend yield.

The reason that can account for this is as follows. In most normal cases, the changes in dividend yield are accompanied by changes in the stock price. Usually, immediately after the payment of the dividends, the stock price will fall by the dividend amount. For those companies whose dividend yield is strikingly high, their stock price drops in value quickly. Besides, the monetary benefits of these dividends can not be gained by holders of the options, but flow to shareholders of the stocks. Combining these factors, when the dividend yield increases, the call value will decrease, but the put value will increase instead [22].

\section{Conclusion}

This paper has explored the valuation of JPMorgan Chase \& Co.'s chooser options, providing some guidance for the investors to choose the best of a chooser call or a chooser put before the maturity date. We constructed a pricing model of the IPM chooser option by virtue of the Black-Scholes simulation model, in which parameters required in the formula are pre-determined from data on different financial websites while stock prices are randomly simulated. 
Our findings disclose that the chooser options have more flexibility in selecting the decision date, but like traditional options, are unable to hedge all the risk that may occur in the capital market though. The payoff is not guaranteed to be perfectly positive and has a chance to bring no gain at all. The chooser options do have downside protection from the money-loss risk, but for the speculators, these are not enough. The relationship between important parameters and option values implies a reasonable utilization of these parameters may benefit the investors. For example, if the decision time is set on the expiration date, the chooser option is sort of a combination of both a call and a put together or a chooser option can be an attractive instrument if the asset witnesses an increase in volatility. Chooser options, constitute a special sort of financial product that requires no immediately predetermined view about the future. The methodology used in this paper can be applied to exploring characteristics of other optional forms as well and can be bettered in order to adapt to more complicated circumstances.

The research our team carried out still has some limitations. We failed to look into the decision date T1 in-depth and to figure out what impacts it may bring to the option values. More investigations are required to set out to examine the precise relationship between these two variables and whether implementation of decision has an optimal date choice, which will be included in our further research.

\section{References}

[1] Mark Rubinstein., 1991. "Exotic Options," Research Program in Finance Working Papers RPF-220, University of California at Berkeley.

[2] Chen, J. (2020, October 26). American Option. Retrieved from Investopedia: https:// www. Investopedia. $\mathrm{com} /$ terms/a/americanoption.asp.

[3] Chen, J. (2021, March 31). European Option. Retrieved from Investopedia: https:// www. Investopedia. $\mathrm{com} /$.

[4] Zhang, P. G. (1997). Exotic Options: A Guide to Second Generation Options. World Scientific Publishing Co. Pte. Ltd.

[5] Je' ro^me Detemple a, Thomas Emmerling. (2009). American chooser options. Journal of Economic Dynamics and Control, 128-153.

[6] MITCHELL, C. (2021, September 9). Chooser Option. Retrieved from Investopedia: https:// www. Investopedia. com/terms/c/chooseroption.asp.

[7] Ingersoll, Jr., J. E. (2000). Digital Contracts: Simple Tools for Pricing Complex Derivatives. The Journal of Business, 73(1), 67-88. https://doi.org/10.1086/209632.

[8] Buchen, P. W. (2004). The pricing of dual-expiry exotics. QUANTITATIVE FINANCE, 101-108.

[9] Government, U. (2020). Large Holding Companies. Washington, D.C.: US Government.

[10] Ali, Z. (2020, April 7). The world's 100 largest banks, 2020. Retrieved from S\&P Global Market Intelligence: https://www.spglobal.com/marketintelligence/en/news-insights/latest-news-headlines/theworld-s-100-largest-banks-2020-57854079.

[11] Co., J. C. (2019). History of Our Firm. Retrieved from JPMorgan Chase \& Co.: https://www. JPMorgan chase. com/about/our-history.

[12] Marcia Millon Cornett, Jamie John McNutt and Hassan Tehranian. (2006). Performance Changes Around Bank Mergers: Revenue Enhancements versus Cost Reductions. Journal of Money, Credit and Banking, 1013-1050.

[13] Gay, G. H. (2018). JPMorgan Chase: a technology company and a bank. Women of Color Magazine, 1821.

[14] Son, H. (2021, July 13). JPMorgan tops estimates after posting $\$ 2.3$ billion boost from better-thanexpected loan losses. Retrieved from CNBC: https://www.cnbc.com/2021/07/13/jpm-earnings-2q-2021-. html (MITCHELL, Chooser Option, 2021).

[15] Co., J. C. (2020). Annual Report 2020. New York: JPMorgan Chase \& Co. Retrieved from https:// www. JPMorgan chase. com/content/ dam/jpmc/ JPMorgan-chase-and-co/ investor-relations/ documents/ annualreport-2020.pdf. 
[16] HAYES, A. (2021, August 22). Volatility. Retrieved from Investopedia: https:// www. Investopedia. com/ terms/v/volatility.asp.

[17] CHEN, J. (2021, September 19). Implied Volatility vs. Historical Volatility: What's the Difference? Retrieved from Investopedia: https://www.investopedia.com/articles/investing-strategy/071616/impliedvs-historical-volatility-main-differences.asp.

[18] MITCHELL, C. (2020, November 7). In the Money (ITM). Retrieved from Investopedia: https:// www. Investopedia. com/terms/i/inthemoney.asp.

[19] MITCHELL, C. (2021, February 16). Out of the Money (OTM). Retrieved from Investopedia: https:// www. investopedia.com/terms/o/outofthemoney.asp.

[20] SETH, S. (2020, April 19). How and Why Interest Rates Affect Options. Retrieved from Investopedia: https://www.investopedia.com/articles/active-trading/051415/how-why-interest-rates-affect-options.asp.

[21] FERNANDO, J. (2021, August 19). Dividend Yield. Retrieved from Investopedia: https:// www. Investopedia. com/terms/d/dividendyield.asp.

[22] BANTON, C. (2020, December 29). Understanding How Dividends Affect Option. 